\title{
Techno-Economic Design of a Stand-Alone Renewable Energy System
}

\author{
S. Abdelkader ${ }^{1,2}$ \\ ${ }^{1}$ Electrical Engineering Department, Faculty of engineering, Mansoura University \\ Mansoura 35516, Egypt \\ e-mail: $\underline{\text { sakader@mans.edu.eg }}$ \\ ${ }^{2}$ School of Electronics, Electrical Engineering \& Computer Science \\ Queen's University Belfast \\ Asbhy Building, Stranmillis Road - Belfast, BT9 5AH (United Kingdom) \\ Phone:+0044 28 90974142, e-mail: s.abdelkader@qub.ac.uk
}

\begin{abstract}
This paper presents a method for the design of a stand-alone renewable energy system supplying an isolated load. In this work, the stand-alone system consists of wind generator, battery storage and backed up by a diesel generator. However, all other forms of renewable energy, storage and backup systems can be included. The proposed method aims at securing the energy needs of the load most economically and reliably through determining the optimum component sizes.

A linear programming model is developed to determine the optimum sizes of system components based on an average day data. Day to day variations are then represented as a stochastic Markov process where an average cycle of the system is constructed and utilized for modifying component sizes to assure the desired level of reliability.
\end{abstract}

\section{Key words}

Wind diesel systems, stand alone system, micro grid, renewable energy

\section{Introduction}

Stand alone renewable energy systems have attracted a great deal of continuous interest over long periods of time extending over almost half a century. This is due to the fact that it represents the most attractive option for powering isolated loads of the small communities scattered in rural area and deserts. Research efforts have been carried out over decades proposing different configurations, design approaches and methods for operation and control of stand alone systems; [1-6] are just examples.

A model based on hour by hour simulation, for the optimum investment choice for autonomous energy systems with renewable sources have been introduced in [1]. The work of [2] finds the optimal technical-economic design of the autonomous system by repeated runs with different system parameters; while [3] presented a model for the optimum operation of an autonomous wind energy supply system with known parameters. In [4], a model for the economic design of the stand alone wind diesel system has been introduced. Although [1-4] are almost three decades old, it has been reviewed just to prove the long interest in the design and operation of stand alone winddiesel systems.

Several recent works also deals with different aspects of the stand alone wind-diesel systems. Areas of interest of recent works include sizing [5-8], planning [9], operation control and management [10-12].

More than other issues the author has worked on, in the renewable energy integration into a power system [1318], the stand alone renewable energy system is attractive. This paper presents a model for designing a stand alone renewable energy system with storage and backup supply. The models and ideas presented are applicable for any combination of renewable energy systems, different energy storage systems and backup generating system. However, in this paper, all presentation is done using a system consisting of a wind generator, battery storage and a diesel generator. The general configuration of the system is shown in Fig. 1. The equipments for energy static conversion which connect the d.c. storage system with the remaining part of the plant are shown. These equipments are:

- a bridge rectifier which converts the energy produced by the wind power generator into d.c. energy and

- an inverter rectifier unit which converts the d.c. energy into a.c. energy at $50 \mathrm{~Hz}$ frequency in the inverter mode and converts the surplus energy produced by diesel electric system into energy which is so able to recharge batteries in the rectifier mode.

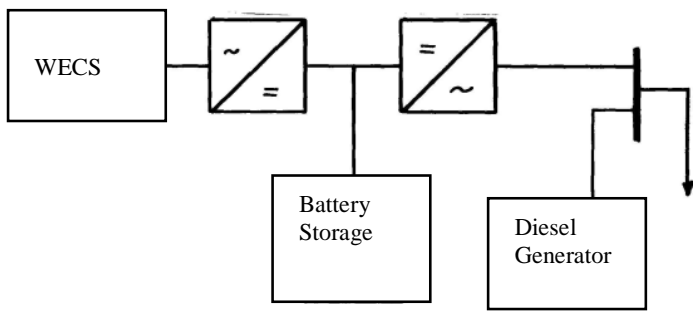

Fig. 1 Power Supply System configuration 
In the proposed method the system component sizes are first determined using a linear programming model. The model uses the data of a representative period to determine the system component sizes and the backup generator operation so that total annual cost minimum. The length of the representative period depends on the variations patterns of the load and weather parameters affecting the power generated from the renewable power generators used. It may be an average day, average week, average month or even the whole year data. Load and renewable power generation are then considered to make the required modifications in the design parameters or the operation of the backup generator to keep a desired reliability level.

It should be mentioned that in case of the availability of different wind generator designs it can be all included in the linear programming model in one go and the model will pick the most economic design, or the most economic combination of the available designs. The next section presents the proposed model and the following sections present results of test cases and discussions.

\section{The proposed model}

The proposed model consists of two main steps; the first step is based on an average daily load curve and an average daily pattern of the Wind Energy Conversion System (WECS) output while the second step takes the day to day variations of both load and WECS into account. In the first step, the optimum design problem of the supply plant is formulated as a linear programming optimization problem. The objective function to be minimized is the total annual cost of the plant. The decision variables are the diesel generator rated capacity and its output power in each hour of the day, battery storage capacity and its charging or discharging power at each hour, the ratings of the power conditioning units and the rated power of the WECS.

In handling the decisions associated with the design of the WECS, a set of alternative designs which differ from each other on the basis of cut-in speed $\mathrm{V}_{\mathrm{ci}}$, rated speed $\mathrm{V}_{\mathrm{r}}$ and cut-out speed $\left(\mathrm{V}_{\mathrm{co}}\right)$ are specified. For each design, the optimum tower height is determined as derived in [19]. For those designs which have a tower height in the practical limits, the wind data of the site are corrected to that height. Then, the relationship between output power and wind speed of each design is approximated by a linear relation in the range $\mathrm{V}_{\mathrm{ci}}<\mathrm{V}<\mathrm{V}_{\mathrm{r}}$ as shown in Fig. 2. Hence, the power generated can be expressed as a function of wind speed as follows:

$p(v)=\alpha P_{r}$

Where;

$\alpha=\left\{\begin{array}{cc}\frac{v-v_{c i}}{v_{r}-v_{c i}} & v_{c i} \leq v<v_{r} \\ 1.0 & v_{r} \leq v<v_{c o} \\ 0, & v<v_{c o} \text { or } v \geq v_{c o}\end{array}\right.$

Then at each interval $\mathrm{i}, \boldsymbol{\alpha}_{i, k}$ is determined using the parameters of the $\mathrm{k}^{\text {th }}$ design alternative with the wind speed data corrected at the optimum tower height for that design. By this method, the rated capacity of the WECSs of different designs can be entered to model as a decision variable. The model then decides how much capacity of each design must be incorporated in the supply plant as well as the other decision variables mentioned before. The calculation steps of the proposed method are illustrated by the flow chart of Fig. 3 below.

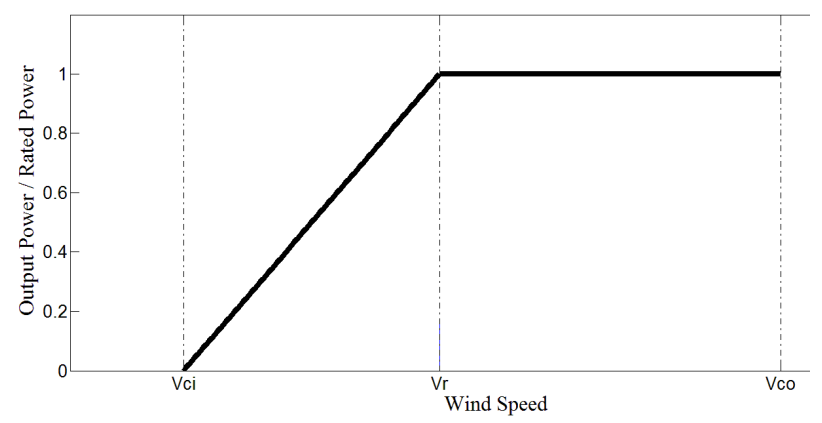

Fig. 2 Linearized WECS characteristics

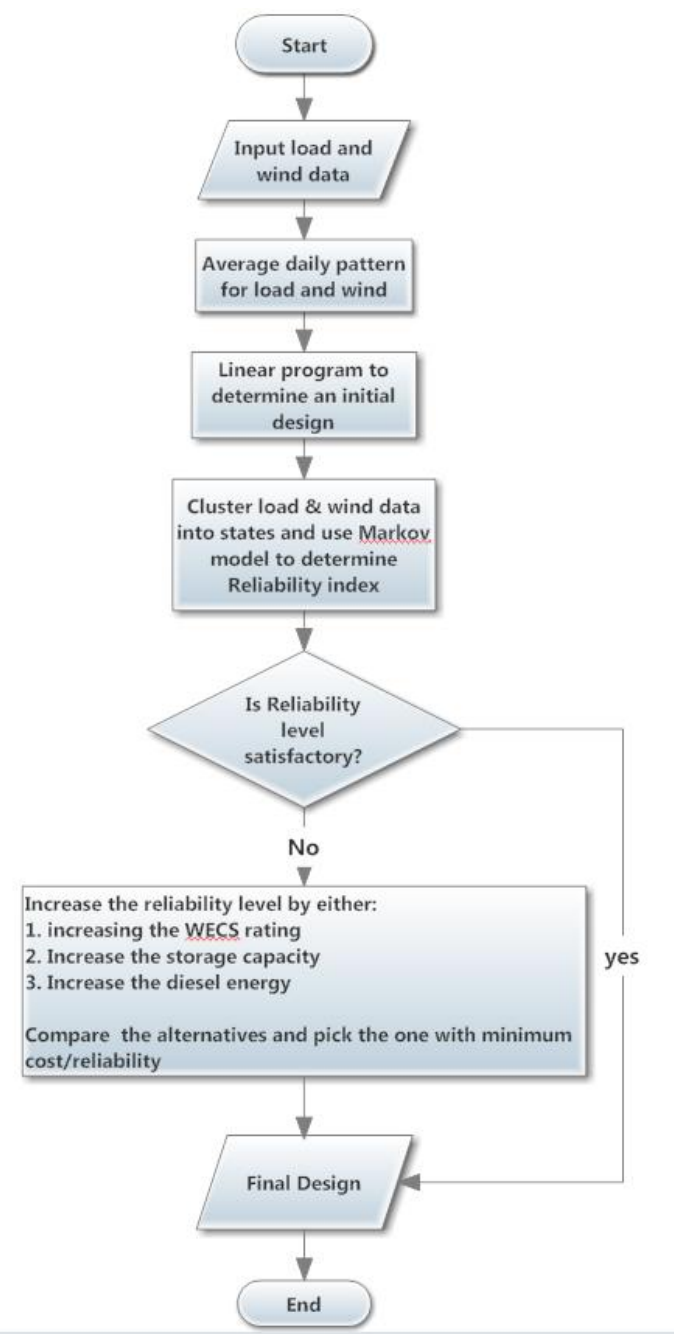

Fig. 3 Flow chart of the proposed method

All of the system design parameters $\left(\mathrm{V}_{\mathrm{ci}}, \mathrm{V}_{\mathrm{r}}, \mathrm{V}_{\mathrm{co}}\right.$, the rated power of the WECS, the rated power and operation strategy of the diesel generator and the storage capacity) are taken into account in this model as decision variables. The model determines the optimum system configuration from both the economical and technical point of view. The total energy not supplied is taken as the reliability index to be minimized and the total annualized cost of the plant is the economic parameter. 


\section{A. The Linear Programming (LP)Model}

It is more straightforward to present the model and then explain what needs explanation. The objective function to be minimized is the total annual cost as given by (3). The power balance (4), battery energy balance (5), battery stored energy level (6), battery energy and deep discharge limits (7)(8), diesel rated power (9), and the rated power of the converter $(10)(11)$ are the constraints for this case. It is straightforward to add other renewable energy sources and/or other forms of storage.

\section{Minimize \\ $F=C D_{1} * P D_{r}+C D_{2} \sum_{i=1}^{T} \Delta t_{i} * P D_{i}+\sum_{k=1}^{m} C W_{k} * P W_{r k}+$ $C S_{0} * Q S+C I R_{0} * P I R$

Suject to

$$
\begin{aligned}
& \boldsymbol{P} \boldsymbol{D}_{\boldsymbol{i}}+\sum_{\boldsymbol{k}=\mathbf{1}}^{K} \boldsymbol{\alpha}_{i, \boldsymbol{k}} * \boldsymbol{P} \boldsymbol{W}_{\boldsymbol{r} \boldsymbol{k}}+\boldsymbol{\eta}_{\boldsymbol{D}} \boldsymbol{q}_{\boldsymbol{D} \boldsymbol{i}-} \frac{\boldsymbol{q}_{c i}}{\boldsymbol{\eta}_{\boldsymbol{c}}}=\mathbf{0}, \boldsymbol{i}=\mathbf{1}, \mathbf{T} \\
& \sum_{\boldsymbol{i}=\mathbf{1}}^{\boldsymbol{T}} \boldsymbol{q}_{\boldsymbol{D} \boldsymbol{i}} \Delta \boldsymbol{t}_{\boldsymbol{i}}=\sum_{\boldsymbol{i}=\mathbf{1}}^{\boldsymbol{T}} \boldsymbol{q}_{\boldsymbol{C} \boldsymbol{i}} \Delta \boldsymbol{t}_{\boldsymbol{i}} \\
& E S_{i}+\Delta t_{i} q_{D i}-E S_{i-1}-\Delta t_{i} q_{C i}=0, \quad i=1, T \\
& \boldsymbol{E} \boldsymbol{S}_{\boldsymbol{i}}-\boldsymbol{Q S} \leq \mathbf{0} \\
& E S_{i}-\gamma Q S \geq 0 \\
& P D_{r}-P D_{i} \geq 0 \\
& P I R_{r}-\left(\sum_{k=1}^{K} \propto_{i, k} P W_{r k}+\eta_{D} q_{D i}\right) \geq 0, \quad i=1, T \\
& P I R_{r}-P D_{i}+P L_{i} \geq 0, \quad i=1, T
\end{aligned}
$$

$C W_{k}:$ cost of design $\mathrm{k}(\$ / \mathrm{kW} /$ year $)$,

$P W_{r k}$ : rated power of design $(\mathrm{kW})$.

$C S O$ : the energy storage cost, $\$ / \mathrm{kWh}$,

$Q S$ : the energy storage capacity, $\mathrm{kWh}$.

$C D_{1}$ : capital cost of diesel generator $\$ / \mathrm{kW} /$ year,

$C D_{2}$ : running cost of diesel generator $\$ / \mathrm{kWhr} /$ year,

$P D_{r}$ : rated power of the diesel generator $\mathrm{kW}$,

$P D_{i}$ : deisel generator output at interval i,

$P L_{i}$ : Load demand at interval i,

$\mathrm{T}:$ the number of intervals in the representative period,

$\Delta t_{i}$ : the duration of interval i.

$C I R_{0}$ : the cost of inverter rectifier system, $\$ / \mathrm{kW}$,

$P I R$ : the power rating of the inverter rectifier unit, $\mathrm{kW}$.

$q_{c i}, q_{d i}$ : battery charging \& discharging powers at interval i,

$\eta_{c}, \eta_{d}$ : battery charging \& discharging efficiencies

$E S_{i} \quad$ : energy stored in the battery at interval i, $\mathrm{kWh}$

$\gamma$ : the minimum allowable discharge level of the battery

Output of the LP optimization model is a system configuration with component sizes and operation strategy that minimizes cost based on the average representative period used. However, wind and load will vary and differ from the used average with the inevitable result of inability to supply load at sometimes, while curtailing some wind power at some other times.

\section{B. Reliability Analysis through Markov Analysis}

The second step of the optimization model is to do some refinements in the system configuration to improve its reliability index. Since the system configuration determined from the linear programming model is based on an average daily load curve and average output of the WECS, then the total annual energy produced by the system is equal to that required by the load. The energy not supplied to load will not result from shortage in energy production, but from mismatch between generation and demand. So, the total energy not supplied can be reduced and thus the system reliability improved by shifting the surplus energy generated in one day to be used in another day, when load is greater than generation, by increasing the battery storage capacity.

To determine the optimum design of the system, that keeps the system reliability index above the acceptable limit with the minimum possible cost, the total annual system cost is calculated as function of the system reliability. To carry out such calculations, the correlation between load and wind and the serial correlation between conditions in successive days should be considered.

This can be done by using the chronological data of both the load and the output of the WECS. At different values of the storage capacity, the total cost of the system and the system reliability are evaluated. Although correct, the chronological simulation has the disadvantage that it requires manipulation of large amount of time series data. In addition, the above calculations have to be repeated at each variation of the storage. This makes the computation time consuming and burdensome.

To take the correlation between load and output of the WECS into account, the data of load demand and WECS output in the form of chronological sequence for each day of the year are clustered. When clustering data, states are identified by a value of load and a corresponding value of the output of the WECS for each state. Then, the chronological data are grouped in these states (clusters) such that all the observations in one state have the tendency to be similar to each other and those in different states tend to be dissimilar. Since the number of states is typically much smaller than the number of observations, the computation burden is significantly reduced. The transition rates between these clusters are also determined during the clustering process. Then, Markov analysis [20] can be carried out to determine the average duration in each state (cluster) to enter into another one. Thus an average cycle for the system can be constructed. This average cycle can be simply used to determine the storage capacity required to keep the system reliability at a specified value.

The chronological data of load and output of the WECS can be converted into a number of states, $\mathrm{N}$, which is much less than the number of original data points. Each of these states is described by a vector D defined as follows:

$\breve{D}^{i}=\left[L^{i}, P_{W}^{i}\right]$

Where $L^{i}$ is the load for state $i$ per unit of the peak load and $\mathrm{P}_{\mathrm{W}}{ }^{\mathrm{i}}$ is the output of the WECS for state $\mathrm{i}$ per unit of its rated capacity. The use of per unit values prevents any variable from dominating the procedure of clustering. When the clustering process is completed, it will be easy to convert the per unit state vectors into energy vectors for the purpose of estimating the system reliability. The energy vector for state $i, D^{i}$, will then be 
$D^{i}=\left[E_{L}^{i}, E_{W}^{i}\right]$

where $E_{L}{ }^{i}$ and $E_{W}{ }^{i}$ are the required demand per day and energy output of WECS per day in state i. They are calculated as follows:

$E_{L}^{i}=L^{i} * L_{\max } * 24$

$E_{W}^{i}=P_{W}^{i} * P W_{r} * 24$

where $\mathrm{L}_{\max }$ is the peak load and $\mathrm{PW}_{\mathrm{r}}$ is the rated power of the WECS.

The state probabilities during one day in terms of that during the preceding day can be expressed as follows:

$\left[\begin{array}{c}P_{1} \\ P_{2} \\ \ldots \\ P_{i} \\ \ldots \\ P_{n}\end{array}\right]^{k+1}=\left[\begin{array}{cccc}t_{11} & t_{12} \ldots & t_{1 j} \ldots & t_{1 n} \\ t_{21} & t_{22} \ldots & t_{2 j} \ldots & t_{2 n} \\ \ldots & \ldots \ldots & \ldots \ldots & \ldots \\ t_{i 1} & t_{i 2} \ldots & t_{i j} \ldots & t_{i n} \\ \ldots & \ldots \ldots & \ldots \ldots & \ldots \\ t_{n 1} & t_{n 2} \ldots & t_{n j} \ldots & t_{n n}\end{array}\right] \cdot\left[\begin{array}{c}P_{1} \\ P_{2} \\ \ldots \\ P_{i} \\ \ldots \\ P_{n}\end{array}\right]^{k}$

$[P]^{k+1}=[T][P]^{k}$

where;

$p_{i}$ : is the probability of being in state $\mathrm{i}$,

$t_{i j}$ : is the transition rate from cluster $\mathrm{j}$ to cluster $\mathrm{i}$,

$\mathrm{k}:$ is an index for the day number,

$\mathrm{T}:$ is the transition rate matrix, $\left[\mathrm{t}_{\mathrm{ij}}\right]$,

$\mathrm{P}:$ is the probability vector.

Such a representation for the system enables us to assess the different alternatives for improving the reliability of the system more simply than using the chronological data of both load and WECS output.

The first step in determining the system reliability is to redistribute the total diesel generated energy on the states. This is done such that in the states with wind energy greater than load energy the diesel will not run. In the other states, the diesel will run for longer time than that determined on the basis of average daily load and wind data. The energy not supplied to load is then determined, if it is found to be below the acceptable limit then the system design obtained from the linear programming model will be the optimum.

The distribution of diesel energy on the system states is done as follows: For the states having $E_{W}^{i} \geq E_{L}^{i}, E_{D}^{i}=0$. For the states having $E_{W}^{i}<E_{L}^{i}, \quad E_{D}^{i}=E_{L}^{i}-E_{W}^{i}$, The following conditions must be satisfied

$E_{D}^{i} \leq E D_{M}$

$\sum_{i=1}^{n} E_{D}^{i} F^{i}=T A D E$

where $\mathrm{n}$ is the number of states, $E_{D}^{i}$ is the diesel generator energy output for state $\mathrm{i}$ and $F^{i}$ is the frequency of state $\mathrm{i}$, and TADE is the total annual output energy of diesel generator. The total energy generated of state i, $E_{G}^{i}$, can then be estimated as:

$E_{G}^{i}=E_{W}^{i}+E_{D}^{i}$

The total energy not supplied (ENS) to the load can then be estimated from the following equation;

$E N S=\sum_{i=1}^{n}\left(E_{L}^{i}-E_{G}^{i}\right) \cdot F^{i} \cdot u\left(E_{L}^{i}-E_{G}^{i}\right)$

It may be more useful and meaningful to express the total energy not supplied in per unit or percent of the annual energy demand.

$E N S(p u)=\frac{E N S}{\text { average load power } * 8760}$
If the energy not supplied to load is found to be greater than the acceptable limit then it must be decreased by one of the alternatives mentioned before. The final decision Is made by the system cost at the desired level of system reliability. If there are no restrictions on the system reliability, the optimum design is taken as that one which minimizes the system cost divided by the system reliability index. In the next section, improving the system reliability by increasing storage capacity is explained.

\section{Improving reliability by increasing the storage size}

The determination of storage capacity requires knowledge of the conditions in successive days. Such information can be gained from the transition rates between states which is used to determine an average cycle of the system states. This average cycle is used for the determination of the storage capacity required to keep a specified value for the system reliability. The average cycle of the system states is constructed by determining the average time spent in each state before leaving to another state. This time is determined using the Markov techniques.

The mean number of steps (days) to reach a particular cluster $\mathrm{j}$ given that the system starts at cluster $\mathrm{i}$ can be found by defining $\mathrm{i}$ as an absorbing state. The average number of steps is then calculated by defining matrix $\mathrm{N}$ as follows [20]:

$N=[I-Q]^{-1}$

Where $\mathrm{Q}$ is a matrix obtained from the transition matrix $\mathrm{T}$ by truncating the $\mathrm{i}^{\text {th }}$ column and the $\mathrm{j}^{\text {th }}$ row. The average duration in state $\mathrm{i}$ before entering state $\mathrm{j}$ is then calculated as follows:

$M_{i j}=\sum_{k=1}^{N-1} \mathbf{N}_{k, j}$

Where $\mathbf{N}$ is the number of states, $\mathbf{M}_{\mathrm{ij}}$ is the average time required to enter state $\mathrm{j}$ given that the system in state $\mathrm{i}, \mathrm{k}$ is an index for rows of the matrix N. As the average time spent in each output state before leaving to another state is determined, an average cycle for the system states can be constructed from which the storage capacity required and the corresponding system cost can be calculated.

\section{Test Example}

To demonstrate the use of the model, the following test_data were used:

Interest rate 15\%; Inflation rate 7\%, Fuel escalation 5\%

Diesel unit cost

Capital costs $\quad \$ 550 / \mathrm{kW}$, Running costs $\quad \$ .15 / \mathrm{kWhr}$

Effective life period 20 years

Cost_of_the_WECS

Design_1

Cost $\$ 1300 / \mathrm{kW}, \mathrm{Vci}, \mathrm{Vr}, \mathrm{Vco}: 5,12,25 \mathrm{~m} / \mathrm{s}$

Design 2

Cost $\$ 1900 / \mathrm{kW}$, Vci, Vr, Vco: 3.5,10, $20 \mathrm{~m} / \mathrm{s}$

Effective life period for both designs 20 years

Battery storage

Cost $\$ 75 / \mathrm{kwh} \quad$ Life period 5 years

Rectifier unit $\$ 500 / \mathrm{kW}$ 
Inverter/Rectifier unit

Wind data

The wind data of Hurgada taken from [21] and an average daily wind pattern is calculated.

Load_data

Hypothetical daily load curve is used; it is shown in Fig. 4.

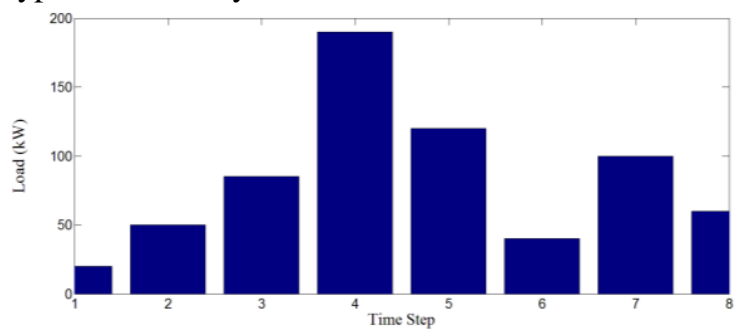

Fig. 4 Load curve

\section{LP Model Results}

Rated power of the diesel generator

$80 \mathrm{~kW}$

Rated power of the WECS

$110 \mathrm{~kW}$

Battery storage capacity

Rectifier unit rating

$270 \mathrm{kWH}$

$110 \mathrm{~kW}$

Inverter/rectifier unit rating

$115 \mathrm{~kW}$

Total annual system cost

$\$ 117760 /$ year

Diesel output energy / load demand

$26.764 \%$

$73.236 \%$

WECS output energy / load demand

$\$ 183950 /$ year

\%age saving by the WECS and the storage

Fig 5 shows the total generation of the system (WECS output and the diesel generator output power) as well as the battery discharging during the whole day. Fig 6 shows the power absorbed, load power and battery charging. Comparing the two figures makes it clear that the power balance constraints are satisfied.

The chronological sequence of wind data are used to estimate the total energy produced by the WECS during each day. The same thing is done for load, but the load data are obtained using a random variable generator to produce a time series of load having the desired average value and standard deviation. The load probability distribution is assumed to be normal distribution.

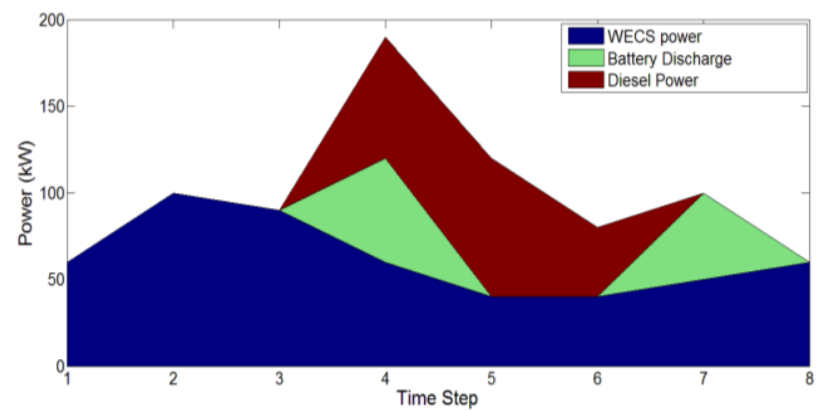

Fig. 5 Total power supplied (WECS+Diesel+Battery Discharge)

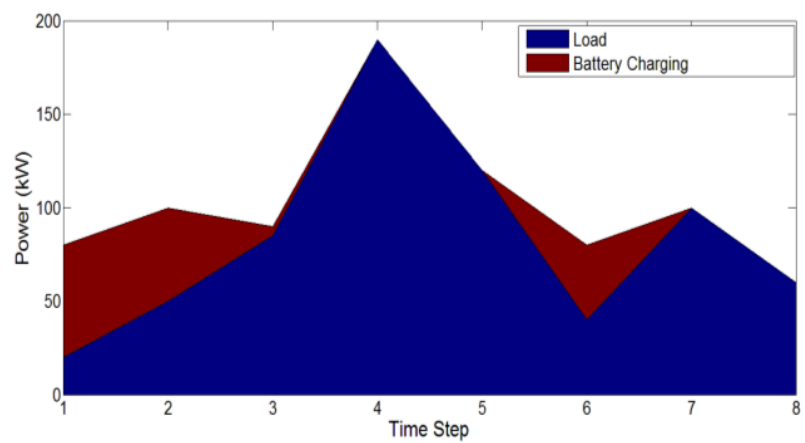

Fig. 6 Total power absorbed (Load+Battery charging)

The energy output of the WECS during each day $E_{W}^{i}$ is divided by the maximum value $E_{W}^{m}$ that had occurred during the whole year. So, we obtain a series of $E_{W}^{i} / E_{W}^{m}$ values that is enclosed in the range, $0<E_{W}^{i} / E_{W}^{m}<1$. The same is done for the load values. Both of the normalized load data and WECS outputs are divided into three classes, this result in 9 states or clusters. The cluster data are shown in the table I. This table shows the cluster centroids, frequency of occurrence and probability. To calculate for the storage capacity, it is more convenient to lump all the similar states in one state.

Table I. - Cluster Parameters

\begin{tabular}{|l|l|l|l|l|}
\hline & \multicolumn{2}{|c|}{ Cluster Centroids } & $\begin{array}{l}\text { Cluster } \\
\text { frequency }\end{array}$ & $\begin{array}{c}\text { Cluster } \\
\text { Prob. }\end{array}$ \\
\hline 1 & $\boldsymbol{E}_{\boldsymbol{W}}^{\boldsymbol{i}} / \boldsymbol{E}_{\boldsymbol{W}}^{\boldsymbol{m}}$ & $\boldsymbol{E}_{\boldsymbol{L}}^{\boldsymbol{i}} / \boldsymbol{E}_{\boldsymbol{L}}^{\boldsymbol{m}}$ & & \\
\hline 2 & 0.1281 & 0.1397 & 48 & 0.1315 \\
\hline 3 & 0.4945 & 0.1404 & 48 & 0.1315 \\
\hline 4 & 0.0828 & 0.1790 & 42 & 0.1151 \\
\hline 5 & 0.4228 & 0.4750 & 54 & 0.1479 \\
\hline 6 & 0.8629 & 0.4321 & 34 & 0.0986 \\
\hline 7 & 0.2123 & 0.7000 & 30 & 0.0821 \\
\hline 8 & 0.5586 & 0.9861 & 31 & 0.0849 \\
\hline 9 & 0.8707 & 0.7090 & 42 & 0.1151 \\
\hline
\end{tabular}

\section{Conclusion}

A model for the optimum design of an autonomous wind diesel system supplying an isolated load is developed. This model determines the system configuration such that the cost/reliability ratio is minimum. This is done in two steps; the first step is an economic optimization model with linear programming solution. This model determines the system configuration on the basis of average daily load curve and average daily pattern of the WECS output. The second step is to do some refinements in the system configuration to minimize the total energy not supplied. In this step, day to day variations in both load and wind energy must be considered. For this purpose, each day of the year is represented by an energy demand for the load and energy output of the WECS. Such representation is sufficient for the isolated areas, because the major part of the load is taken for water pumping for irrigation or for water desalination. Such loads can be met when energy is available at any time of day. The clustering technique is used for grouping the chronological data of load and wind into a smaller number of states which can be used for estimating the system reliability. From the results of this model we can conclude that adding wind energy system to the remote loads supply plant is more economic than using a diesel generator alone.

The alternatives available for improving the system reliability are to increase the storage capacity, to increase the diesel generator output energy or to increase the WECS capacity. It is found that increasing the WECS capacity is the most economic alternative.

\section{Acknowledgement}

This work was supported in part by Science Foundation Ireland (SFI) through the Charles Parsons Energy Research Award: 06/CP/E002.. 


\section{References}

[1] K. Blok, et al, "Optimum investment choice for autonomous energy systems", Proceedings of the European Wind Energy Conference EWEC'86, Rome, Italy October 7-9, 1986.

[2] E. Campanari, et al,"Technical- Economic optimal evaluation of a wind energy for supplying an isolated load", Proceedings of the European Wind Energy Conference EWEC'86, Rome, Italy October 7-9, 1986.

[3] G. C. Contaxis, et al "Optimum operation of an autonomous energy system" , Proceedings of the European Wind Energy Conference EWEC'86, Rome, Italy October 7-9, 1986.

[4] S. Abdelkader, "Techno-economic assessment of wind energy potential and conversion systems in Egypt", M. Sc. Thesis, Mansoura University, Egypt, 1989.

[5] Y. Hong \& R. Lian, "Optimal Sizing of Hybrid Wind/PV/Diesel Generation in a Stand-Alone Power System Using Markov-Based Genetic Algorithm", IEEE Transactions on Power Delivery, Vol. 27, No.2, pp. 640-647, 2012.

[6] M. Ross, C. Abbey \& G. Joos, "Cost analysis for sizing energy storage systems in wind-diesel microgrids", IEEE Power and Energy Society General Meeting, 2011.

[7] M. Arriaga, C. A. Canizares, and M. Kazerani, "Renewable Energy Alternatives for Remote Communities in Northern Ontario, Canada", IEEE Transactions on Sustainable Energy, Vol. 4, No.3, pp. 661-670, 2013.

[8]..F. Katiraei, and C. Abbey, "Diesel Plant Sizing and Performance Analysis of a Remote Wind-Diesel Microgrid", IEEE Power Engineering Society General Meeting, 2007.

[9]..L. Guo, W. Liu, B. Jiao, B. Hong \& C. Wang, "Multiobjective stochastic optimal planning method for stand-alone microgrid system", IET Gener. Transm. Distrib., Vol. 8, No. 7, pp. 1263-1273, 2014.

[10].R. Sebastian, "Simulation of the Transition from Wind only Mode to Wind Diesel Mode in a No-Storage Wind Diesel System", IEEE Latin America Transactions, Vol. 7, No. 5, pp. 539- 544, 2009.
[11] A. Haruni, A. Gargoom, M. Haque, and M. Negnevitsky," Dynamic operation and control of a hybrid wind-diesel stand alone power systems", Twenty-Fifth Annual IEEE Applied Power Electronics Conference and Exposition (APEC), pp. 162169, 2010.

[12] R. Palma-Behnke, C. Benavides, F. Lanas, B. Severino, L. Reyes, J. Llanos, \&.D. Saez, "A Microgrid Energy Management System Based on the Rolling Horizon Strategy", IEEE Transactions on Smart Grid, Vol. 4, No.2, pp. 996-1006, 2013.

[14] S. Abdelkader, D. Flynn, "Graphical determination of network limits for wind power integration", IET Gener. Transm. Distrib. Vol. 3, No. 9, pp. 841-849, 2009.

[15] J Fu, S Abbott, B Fox, DJ Morrow, S Abdelkader, "Wind cooling effect on dynamic overhead line ratings", 45th International Universities Power Engineering Conference (UPEC), 2010.

[16] S Abdelkader, S Abbott, J Fu, B Fox, D Flynn, L McClean, L Bryans, "Dynamic monitoring of overhead line ratings in wind intensive areas", European Wind Energy Conf.(EWEC), 2009.

[17] S. Abdelkader, D. J. Morrow, "Online tracking of Thévenin equivalent parameters using PMU measurements", IEEE Transactions on Power Systems, Vol. 27, No.2, pp. 975983.

[18] S. Abdelkader, "Complex power flow tracing for transmission loss allocation considering loop flows", IEEE PES GM 2009.

[19] S. Abdelkader, "Analytical Expression For The Tower Height of WECS", International Conference on Renewable Energies and Power Quality (ICREPQ'14), Cordoba, Spain, 2014.

[20] R. Billinton and R. N. Allan, "Reliability evaluation of power systems", Pitman Books Ltd.,1984

[21] M. A. Saleh and N. M. A. Moubarak, "Wind Energy", a report of the supreme council of the new and renewable energies, Ministry of Electricity and Energy, Egypt, 1984 